\title{
EROSÃO DOS SOLOS EM GOIÂNIA-GO SOB O ENFOQUE DO JORNAL DIÁRIO DA MANHÃ
}

\author{
Bruna Fernandes Lopes ${ }^{(a)}$, Andrelisa Santos Jesus ${ }^{(b)}$

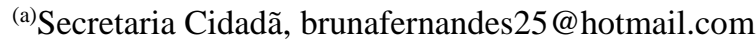 \\ (b)Professora do Instituto de Estudos Socioambientais, Universidade Federal de Goiás ,andrelisajesus @ gmail.com
}

\section{Eixo: GEOGRAFIA FÍSICA E DESASTRES NATURAIS}

\begin{abstract}
Resumo
Como consequência da grande quantidade de problemas ao meio físico e socioeconômico relacionados a desastres naturais como os processos erosivos, essa questão passou a aparecer com mais frequiência nos noticiários. Diante disso, esta pesquisa analisou a abordagem de erosão de solos na cidade de Goiânia pelo jornal Diário da Manhã. Desta forma, propôs-se identificar e quantificar reportagens sobre erosões, sendo que o levantamento das matérias jornalísticas totalizou 59 reportagens que abordavam os processos erosivos e suas repercussões em Goiânia-GO. Foi possível notar que a maioria das notícias e análises sobre os acidentes e/ou riscos de acidentes em áreas afetadas por processos erosivos possuem abordagens pontuais que não enfatizam de forma integrada causas e consequências do fenômeno.
\end{abstract}

Palavras chave: Processos erosivos, desastres naturais, jornal.

\section{Introdução}

Os desastres naturais podem ser provocados por diversos fenômenos, tais como: inundações, escorregamentos, erosão, terremotos, tornados, furacões, tempestades, estiagem, entre outros (INSTITUTO GEOLÓGICO, 2009). Os processos erosivos ocorrem espontaneamente devido a dinâmica natural do planeta (Ranhe et al, 2012) e, embora, sejam um fenômeno natural, envolvidos em processos geológicos e geomorfológicos de esculturação da superfície terrestre, podem ser acelerados por meio da utilização inadequada do solo.

Os fatores que deflagram processos de erosão são multivariados e se correlacionam. A ocupação humana iniciada pelo desmatamento e seguida pelo cultivo da terra, construção de estrada, criação e expansão das cidades, sobretudo quando efetuada de modo inadequado, constitui fator decisivo para aceleração de tais processos (SALOMÃO E IWASA, 1995).

Diversas são as consequências do desenvolvimento das erosões em áreas urbanas, além das perdas de áreas produtivas, destruição de casas, estradas e obras públicas, as erosões contribuem também para o assoreamento de rios e reservatórios, propiciando enchentes, prejuízos no abastecimento e produção de energia elétrica, contaminação de mananciais e desenvolvimento de focos de doenças. Jesus (2013) aponta 
que essa problemática ambiental, afeta diretamente a qualidade de vida de toda população, atingindo desde a saúde até o mercado imobiliário.

Como conseqüência da grande quantidade de problemas ao meio físico e socioeconômico relacionados a processos erosivos, a questão das erosões passou a aparecer com mais freqüência nos noticiários.

\section{Materiais e Métodos}

Para a execução desta pesquisa, foi feito o levantamento das notícias publicadas sobre processos erosivos e suas repercussões na cidade de Goiânia. Optou-se por trabalhar com veículos de comunicação impresso do tipo jornal. O Jornal Diário da Manhã foi selecionado pelos seguintes motivos: segundo Abrahão (2005), O Diário da Manhã é um dos jornais de maior circulação em Goiânia, portanto atinge um maior público e esse jornal disponibiliza seus exemplares impressos em formato digital em seu portal de notícias na internet, sendo possível acessar essas notícias de forma gratuita.

Foram consultadas no arquivo desse jornal suas edições diárias para todos os meses dos anos de 2011, 2012, 2013 e 2014. A coleta das notícias teve como critério de seleção as palavras buraco (s), cratera (s), vala (s), valeta (s), erosão (ões), ravina (s) e voçoroca (s). Utilizando esse critério de seleção para as matérias analisadas, foram encontradas o total de 59 matérias que abordavam erosão sob os mais diferentes contextos na cidade de Goiânia.

Essas matérias foram catalogadas em um banco de dados construído no Software Excel, onde foi feita a categorização das informações e quantificação dos eventos erosivos de acordo com o local de ocorrência. Por fim, os eventos foram especializados em mapa utilizando-se o shape de setores em conjunto com o shape de bairros da base de dados do Plano Diretor da Região metropolitana de Goiânia.

Nesse mapa as regiões de Goiânia mencionados nas matérias jornalísticas foram indicadas utilizando-se a linguagem semafórica, indo do verde ao vermelho para menor e maior número de matérias, respectivamente, sendo a cor branca utilizada para áreas em que não foi registrada nenhuma matéria jornalística.

\section{Resultados e Discussões}

O levantamento das matérias jornalísticas entre os anos de 2011 a 2014, no portal de notícias do Jornal Diário da Manhã, totalizou 59 reportagens trazendo os processos erosivos e suas repercussões no município de Goiânia. 


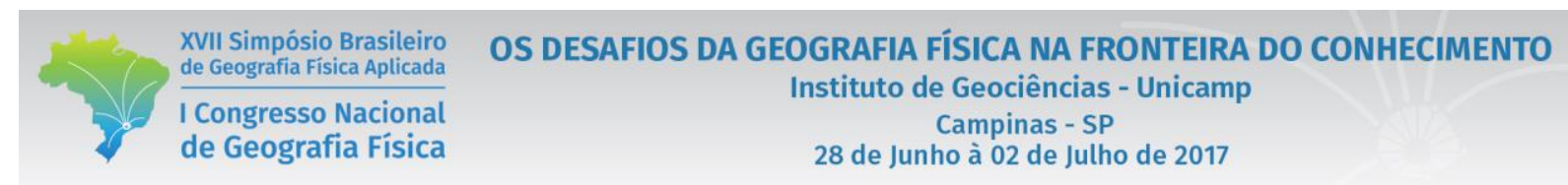

Maria Amélia Nascimento em 1994, juntamente com os alunos do curso de Geografia da Universidade Federal de Goiás, fez um levantamento e cadastramento das voçorocas do município de Goiânia, foram cadastradas 45 voçorocas e a maioria dessas voçorocas estavam situadas na região leste do município (Nascimento, 1994). A partir da análise das matérias, notou-se que os processos erosivos continuam se destacando na região leste do município, sendo que essa região aparece com o maior número de reportagens mencionando processos erosivos (Figura 1). Das 59 matérias abordando processos erosivos em Goiânia, 18 delas ocorrem nos setores da região leste do município (Figuras 2 e 3).

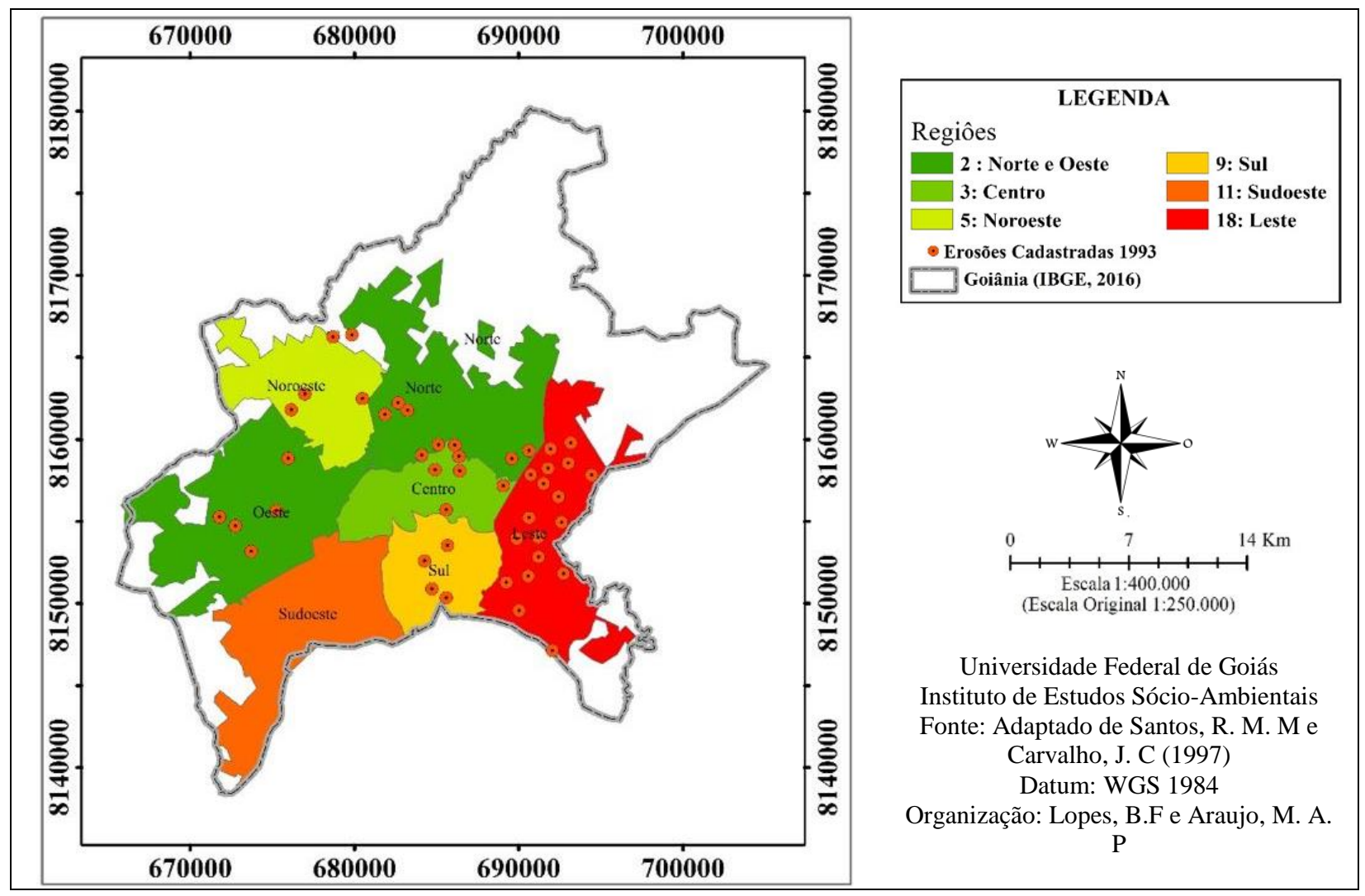

Figura 1: Distribuição espacial das erosões abordadas nas matérias de jornal. 


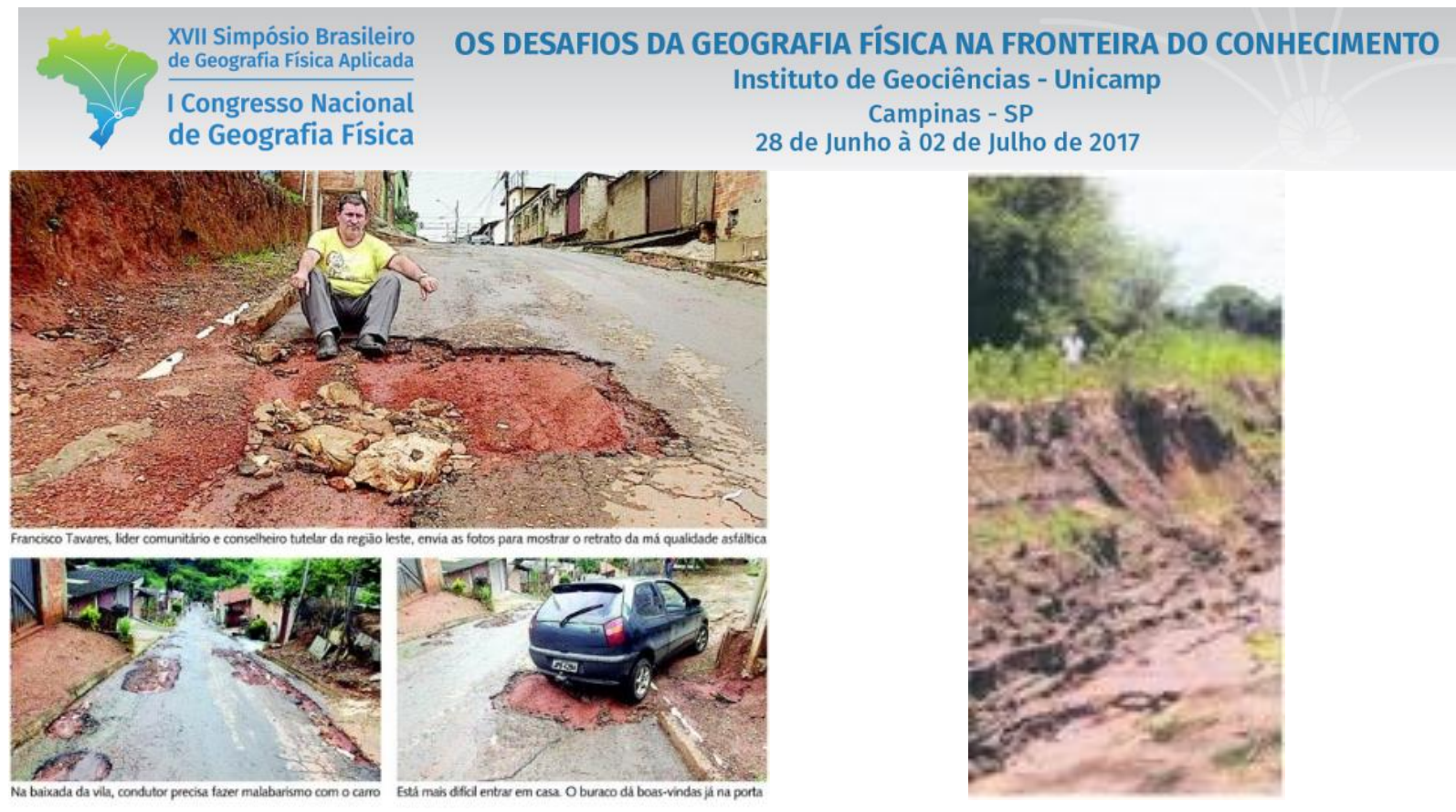

Figura 2: Processos erosivos em ruas do bairro Vila Maria

Luiza na Região Leste Fonte: Jornal Diário da Manhã, $10 / 01 / 2012$

Figura 3: Taude de erosão na Região Leste. Fonte: Jornal Diário da Manhã, 05/01/2012

Nascimento (1994) constatou que o crescimento mal planejado da cidade favoreceu o surgimento de processos erosivos, e os problemas do centro da cidade como lançamento de esgoto e águas servidas através de galerias pluviais à meia encosta, foram transferidos para a periferia do município, que é o caso da região leste. Além disso, na região leste o relevo esculpido sobre xistos do Grupo Araxá com intercalações quartzíticas proporcionou uma dissecação mais acentuada da superfície influenciando na cobertura pedológica, onde destacam-se os Cambissolos. Essas características do meio físico configuram uma maior suscetibilidade natural a ocorrência de erosões do solo.

A Figura 4 apresenta qualitativamente as seguintes categorias de danos relacionados aos processos erosivos sobre a população de acordo com o informado pelo Jornal Diário da Manhã: comprometimento da Via; Acidentes; Prejuízos a Trafegabilidade; Danos Veiculares; Danos à Saúde; Acúmulo de Lixo; Assoreamento; Desconforto da População; Outros e Não Informados. Dentre as categorias analisadas os acidentes se desatacaram, sendo registrados em 39,83\% das matérias analisadas, envolvem desde o risco de queda de pessoas, carros e motos dentro da erosão. Os prejuízos a trafegabilidade e comprometimento da via são danos que foram abordados em $23,7 \%$ e 19,49\% das matérias, respectivamente (Figura 2). Esses dois danos estão interligados, pois o comprometimento da via prejudica diretamente a trafegabilidade das pessoas e dos seus meios de transportes. Além disso, ambas as categorias podem desencadear alguns dos acidentes mencionados anteriormente. 


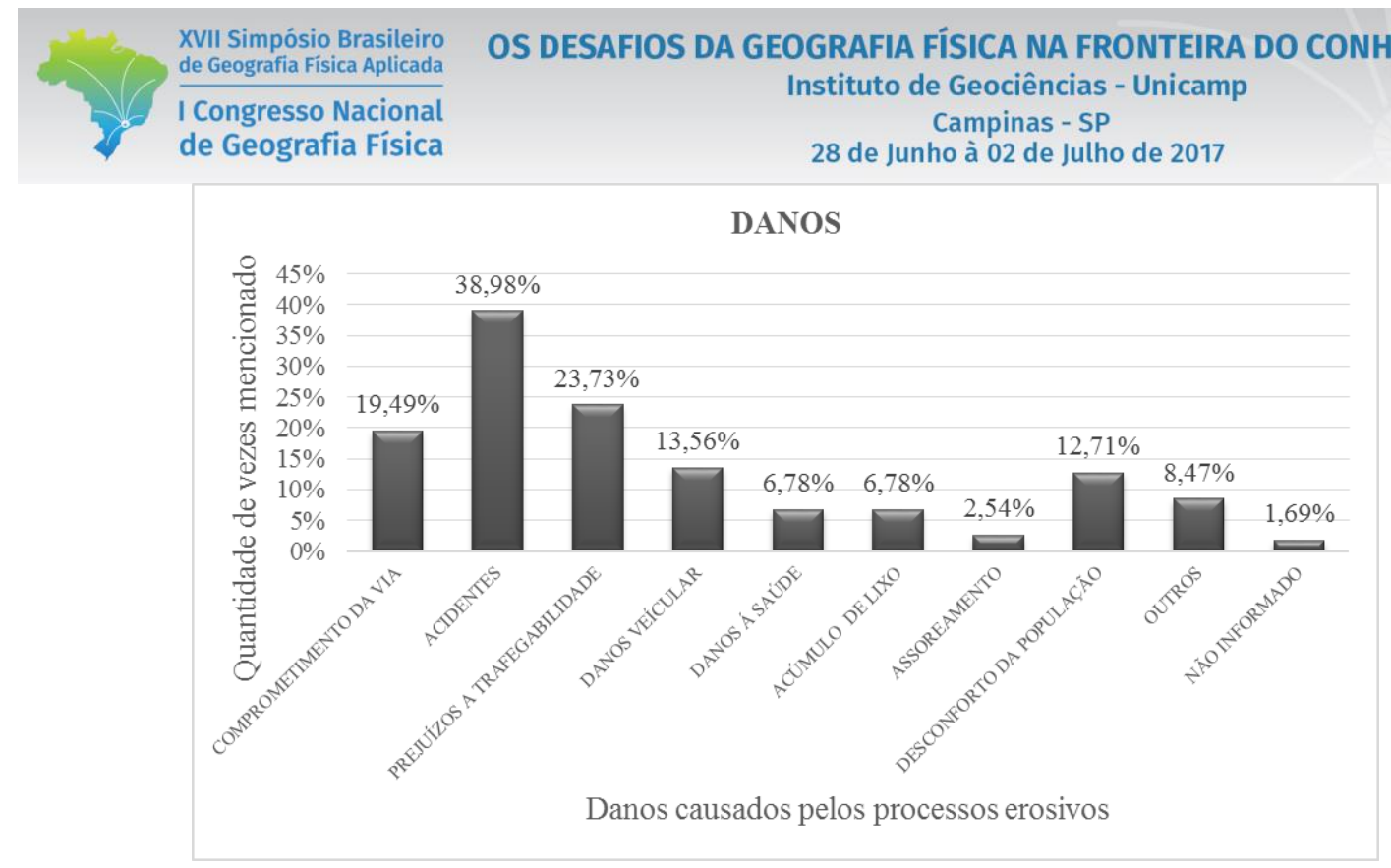

Figura 4: Danos noticiados no Jornal Diário da Manhã de 2011 a 2014.

\section{Considerações Finais}

Embora a maioria das notícias analisadas utilizam termos sensacionalistas e alarmantes que, em geral, não descrevam e explicitem com a devida importância as causas e consequências de processos erosivos essas notícias podem ser utilizadas como um dos instrumentos para mapeamento de áreas de risco na cidade.

Para além da abordagem jornalística, os dados veiculados permitiram verificar que parece não haver uma preocupação do poder público em mitigar e prevenir desastres naturais relacionados a erosões, uma vez que o jornal tem noticiado problemas relacionados a erosões em regiões da cidade onde já em 1994 pesquisadores constaram um alto número de processos erosivos do tipo voçoroca. Mais de 20 anos depois de cadastradas, erosões continuam gerando matérias jornalísticas que tratam dos impactos dessas feições para a população local.

\section{Bibliografias}

ABRAHÃO, Vera Lúcia Escobar Oliveira. A linguagem em foco: Uma análise da linguagem jornalística em textos de jornais diários de Goiânia. 2005. 189 f. Monografia - Curso de Jornalismo, Universidade Federal de Goiás, Goiânia, 2005.

BELMONTE, Roberto Villar. Cidades em Mutação: Menos Catástrofes e Mais Ecojornalismo. In: BOAS, Sergio Vilas (Org.). Formação e Informação Ambiental: Jornalismo para Iniciados e Leigos. São Paulo: Summus, 2004.

DESASTRES NATURAIS: conhecer para prevenir / Lídia Keiko Tominaga, Jair Santoro, Rosangela do Amaral (orgs.) -. São Paulo: INSTITUTO GEOLÓGICO, 2009. 
GIRARDI et al. Pensando o Jornalismo Ambiental na ótica da Sustentabilidade. UNIrevista - Vol. 1, $\mathrm{n}^{\circ} 3.2006$. ISSN 1809-4561

JESUS, Andrelisa Santos de. Investigação multidisciplinar de processos erosivos lineares: estudo de caso da cidade de Anápolis - GO. 2013. xxvii, 340 f., il. Tese (Doutorado em Geotecnia) — Universidade de Brasília, Brasília, 2013.

NASCIMENTO, M.A.L.S. Erosões Urbanas em Goiânia. Boletim Goiano de Geografia, v. 14, n. 1, p. 77-101, 1994.

SALOMÃO, F.X.T.; IWASA, O.Y. Erosão e ocupação rural e urbana. In: $4^{\circ}$ Curso de geologia aplicada ao meio ambiente. São Paulo, ABGE/IPT, 1995. 